\title{
How and When Retailers' Sustainability Efforts Translate into Positive Consumer Responses: The Interplay Between Personal and Social Factors
}

\author{
Dianne Hofenk $^{1} \cdot$ Marcel van Birgelen ${ }^{2} \cdot$ Josée Bloemer $^{2} \cdot$ Janjaap Semeijn $^{3}$
}

Received: 15 July 2016/ Accepted: 16 June 2017

(c) The Author(s) 2017. This article is an open access publication

\begin{abstract}
This study aims to address how (through which mechanisms) and when (under which conditions) retailers' sustainability efforts translate into positive consumer responses. Hypotheses are developed and tested through a scenario-based experiment among 672 consumers. Retailers' assortment sustainability and distribution sustainability are manipulated. Retailers' sustainability efforts lead to positive consumer responses (e.g., improved store evaluations) via two underlying mechanisms: consumers' identification with the store (personal route) and store legitimacy (social route). The effects of sustainability efforts are strengthened if consumers have personal norms favoring shopping at environmentally friendly stores. Remarkably, when controlling for moderation by personal norms, social norms weaken the effects. The findings show that traditional marketing mix elements provide opportunities for retailers to improve their organizations' bottom line and positively affect consumer (and societal) well-being. This study helps retailers decide whether or not to invest in and communicate about sustainability. Past research has shown the clear potential for positive consumer responses to firms' sustainability efforts, but little is known about the underlying mechanisms and the conditions under which
\end{abstract}

Dianne Hofenk

diannehof@hotmail.com

1 EDM, P.O. Box 2700, 3430 GC Nieuwegein, The Netherlands

2 Institute for Management Research, Radboud University Nijmegen, P.O. Box 9108, 6500 HK Nijmegen, The Netherlands

3 School of Management, Open University of the Netherlands, P.O. Box 2960, 6401 DL Heerlen, The Netherlands such responses take place. This study advances theory by examining personal and social factors as mediators and moderators of the retailers' sustainability efforts-consumer responses relationship.

Keywords Consumer responses - Identification · Legitimacy · Personal norms - Retailing - Social norms · Sustainability

\section{Introduction}

The success of multinational home products company IKEA in selling sustainable products ( $\$ 1.13$ billion in 2014, an increase of $58 \%$ over 2013) clearly signifies positive consumer responses to a retailer's sustainability efforts (EcoWatch.com 2015). According to the literature, such efforts may lead to increases in product preference (Luchs et al. 2010), firm market value (Luo and Bhattacharya 2006), positive company evaluations and purchase intentions (Mohr and Webb 2005; Sen and Bhattacharya 2001; Wagner et al. 2009; Yoon et al. 2006), repeat patronage and recommendation intentions (Vlachos et al. 2009), brand choice (Barone et al. 2000; Henderson and Arora 2010), customer donations to corporate-supported nonprofit groups (Lichtenstein et al. 2004), and other forms of consumer support (Handelman and Arnold 1999).

On the other hand, many consumers are skeptical (e.g., Hsu 2011), and recent research (Luchs et al. 2010; Wagner et al. 2009; Yoon et al. 2006) suggests that positive consumer responses are not guaranteed. Some consumers are more likely to respond positively than others, and some circumstances strengthen or weaken the effects. From a marketing perspective, knowledge on such moderators of the sustainability efforts-consumer responses relationship 
is needed to help retailers in making their efforts more effective. ${ }^{1}$ In addition, understanding how (through which mediating mechanisms) these efforts translate into positive consumer responses would provide further assistance. Despite growing research on the outcomes of sustainability, extant research into the underlying mechanisms is scarce (Bhattacharya et al. 2009; Yoon et al. 2006). This study therefore aims to address how (through which mechanisms) and when (under which conditions) retailers' sustainability efforts translate into positive consumer responses. We thereby focus on personal versus social factors, inspired by previous studies in the field of marketing and consumer behavior, in particular pro-environmental behavior.

Personal and social (or subjective) norms have a prominent role in the pro-environmental behavior literature, affecting, for instance, consumer recycling behavior (Oom Do Valle et al. 2005), and drivers' intentions to reduce their car use for commuting (Wall et al. 2007). When consumers have stronger personal and social norms favoring certain behavior, they should be motivated to conform to these norms and behave accordingly (Schuler and Cording 2006). It is particularly interesting to jointly examine personal and social norms since it sheds light on whether sustainable consumer behavior is motivated by norms that are internally held or externally imposed, or both. Some studies in the pro-environmental behavior field show that the effect of social norms becomes nonsignificant if personal norms are included (e.g., Wall et al., 2007), or the other way around (e.g., Bamberg and Schmidt 2003). In the sustainable or ethical marketing literature, the joint examination of personal and social norms has received less attention, although work by Shaw and colleagues examined the effects of subjective norms and a construct similar to personal norms, ethical obligation, on intention to purchase fair trade grocery products. Their studies show mixed effects as well (Ozcaglar-Toulouse et al. 2006; Shaw and Shiu 2002, 2003; Shaw et al. 2000). In further support of our research on the effects of personal and social norms on sustainable consumer behavior are the suggestions by Vitell (2015), who argues that future research should focus on identifying the characteristics of people who are socially responsible and of those who are not, as well as the influence of family and friends on ethical decision making.

To understand how (through which mechanisms) retailers' sustainability efforts translate into positive consumer responses, we build upon work by Sen and Bhattacharya (2001) and Handelman and Arnold (1999). Again,

\footnotetext{
${ }^{1}$ However, from an ethics perspective (as one of the reviewers pointed out), the question can be asked whether informing companies how they can manipulate consumer behavior in order to increase the effectiveness of their sustainability efforts is ethical. We address this question in the discussion part of this paper.
}

we are triggered by personal versus social factors. The few studies that have investigated the mediating mechanisms underlying the sustainability efforts-consumer responses relationship mainly focused on personal factors, in particular emotion-laden processes such as consumer-firm emotional attachment (Vlachos 2012) and consumercompany congruence or identification (Sen and Bhattacharya 2001). An alternative route, proposed by Handelman and Arnold (1999), focused on a social factor, namely organizational legitimacy, which is "a generalized perception or assumption that the actions of an entity are desirable, proper, or appropriate within some socially constructed system of norms, values, beliefs, and definitions" (Suchman 1995, p. 574). Given that many companies try to improve their legitimacy and secure their license to operate through sustainability efforts (Aguilera et al. 2007), it is surprising that this route has not been examined in more detail in the marketing literature. Our study aims to advance theory by examining these personal (consumercompany identification) and social routes (perceived organizational legitimacy) simultaneously, allowing for a theoretical and empirical comparison of the two routes and providing insight into the workings and relative importance of each of them.

In the remainder of this article, we begin with a theoretical background and development of hypotheses, followed by a presentation of the scenario-based experimental design we used to test the hypotheses. Then we report the results and conclude with theoretical and managerial implications, limitations, and suggestions for further research.

\section{Theoretical Background and Hypotheses Development}

\section{Sustainability, Corporate Social Responsibility, and Consumer Social Responsibility}

Sustainability has become an important theme in society. Governments, companies, and individuals increasingly express their concern for the natural and social environment, which they are part of and which is affected by their behavior. In 1987, the World Commission on Environment and Development published "Our Common Future" in which they called for sustainable development, or development that "meets the needs of the present without compromising the ability of future generations to meet their own needs" (p. 43). Accordingly, companies have adopted the idea of the triple bottom line, which holds that business performance should be assessed on social justice, environmental quality, and economic prosperity also referred to as People, Planet, Profit (Elkington 1999). 
Related to sustainability is the concept of Corporate Social Responsibility (CSR), whereby a CSR-focused business can be defined as one that "proactively offers social benefits or public service, and voluntarily minimizes practices that harm society, regardless of any legal requirements" (Vitell 2015, p. 767). For CSR to be successful however, the assistance of consumers is needed: They should be willing to support companies that practice CSR and buy their products or services. Without consumer support, CSR would often not lead to business success.

This consumer support for CSR is called Consumer Social Responsibility (CnSR) by Vitell (2015). More precisely, consumer ethics/social responsibility is defined as "the moral principles and standards that guide the behaviors of individuals as they obtain, use, and dispose of goods and services" (Muncy and Vitell 1992, p. 298). Based on this definition, two consumer responsibilities are distinguished. First, consumers should act ethically toward other stakeholders when they obtain, use, and dispose of goods and services (i.e., consumer ethics). Second, consumers have a responsibility to society as a whole to avoid practices that harm society and to act proactively for social benefit with regard to obtaining, using, and disposing of products (i.e., CnSR) (Vitell 2015). The latter is in line with the fifth dimension of the consumer ethics scale, which constitutes positive (ethical) actions of consumers, namely "doing good/recycling." This dimension has been recently added to the four original dimensions of the consumer ethics scale (actively benefiting from illegal activities, passively benefiting, actively benefiting from questionable (but perceived to be legal) acts, and no harm/ no foul), thereby increasing the scope of consumer ethics to include CnSR (Muncy and Vitell 1992; Vitell 2015; Vitell and Muncy 2005).

\section{Retailers' Sustainability Efforts and Consumer Responses}

We examine consumer social responsibility in relation to obtaining products from retailers by studying the effects of two sustainability efforts covering two elements of the marketing mix: assortment sustainability (Product) and distribution sustainability (Distribution). Building an attractive assortment and getting products close to consumers are two important functions of retailers through which they serve their customers. These functions offer considerable opportunities to increase retailers' sustainability, for example by including environmentally friendly or fair trade products in the assortment. We focus on environmental aspects of sustainability and define assortment sustainability as the environmental friendliness of products sold by the retail store, according to their overall life cycle (from raw materials to waste). In terms of distribution, we examine how stores located in urban areas obtain supplies (i.e., urban distribution), which directly affects the quality of life of consumers, citizens, and communities in the form of local emissions, noise, and congestion (Quak and De Koster 2007). In line with efforts to optimize urban distribution (Browne et al. 2005), we define distribution sustainability as the environmental friendliness of the method in which a store is supplied. The examination of assortment sustainability and distribution sustainability answers the call for research to consider multiple sustainability efforts and their unique effects (Aguilera et al. 2007; Godfrey et al. 2009; Peloza and Shang 2011). A systematic review by Peloza and Shang (2011) revealed that most researchers use a single effort.

In general, companies' sustainability efforts prompt positive consumer responses (Brown and Dacin 1997; Handelman and Arnold 1999; Mohr and Webb 2005), because most people regard sustainability positively and associate it with moral fairness and universal justice norms (Aguilera et al. 2007). Since these positive effects can be very much expected, we do not state formal hypotheses about them. Following the definition of CnSR (Vitell 2015), socially responsible consumers have the responsibility to society as a whole to shop at stores with a sustainable assortment and distribution. However, not all consumers act in a socially responsible way when obtaining products. For them, other (self-interest related) attributes such as price might be more important. The difference between socially responsible and nonresponsible consumers might be caused by certain personal characteristics or social conditions (Vitell 2015). Therefore, we focus on personal and social factors that are expected to mediate and moderate the sustainability efforts-consumer responses relationship. In doing that, we consider four responses that are relevant to retailers: store evaluations (Yoon et al. 2006), intentions to shop at the store (Handelman and Arnold 1999), word-of-mouth intentions, and willingness to pay more (Zhang and Bloemer 2008).

\section{Mediation by Identification and Store Legitimacy}

We propose two theoretical concepts that offer a personal and social route through which retailers' sustainability efforts may translate into positive consumer responses: consumers' identification with the retail store and perceived store legitimacy, respectively. Identification is "the perception of oneness with or belongingness to" an organization (Ashforth and Mael 1989, p. 21). According to social identity theory, people often identify with organizations (or subgroups in organizations) to which they belong (Bhattacharya et al. 1995; Mael and Ashforth 1992). Such organizational identification helps people achieve their desire for self-definition (Ashforth and Mael 1989; Bhattacharya and 
Sen 2003). They do not need to be formal members of an organization (e.g., employees) to identify with it; consumers can identify with organizations from which they buy products (Lichtenstein et al. 2010; Sen and Bhattacharya 2001). Since sustainability is generally regarded positively (Aguilera et al. 2007), we propose that consumers are more likely to identify with stores that employ sustainability efforts and "do good," because such identification can enhance their self-esteem (Bergami and Bagozzi 2000; Mael and Ashforth 1992). Because organizational identification in turn enhances people's support for an organization (Sen and Bhattacharya 2001), we posit:

H1: The effects of assortment sustainability and distribution sustainability on (a) store evaluations, (b) shopping intentions, (c) word-of-mouth intentions, and (d) willingness to pay more are mediated by consumers' identification with the store.

The social route-mediator we propose is organizational legitimacy, which reflects the desirability or appropriateness of an organization's actions within institutional norms (Suchman 1995). Legitimacy is a key construct in institutional theory, such that

Organizations are driven to incorporate the practices and procedures defined by prevailing rationalized concepts of organizational work and institutionalized in society. Organizations that do so increase their legitimacy and their survival prospects, independent of the immediate efficacy of the acquired practices and procedures (Meyer and Rowan 1977, p. 340).

Legitimacy is necessary to obtain stakeholder (e.g., consumer) support (Kumar and Das 2007; Zimmerman and Zeitz 2002) and can reflect pragmatic (i.e., self-interested) or moral (i.e., normative) considerations (Suchman 1995). Because social responsibility has become an important institutional norm in societies nowadays (Aguilera et al. 2007), we argue that a store's sustainability efforts contribute to consumers' perceptions of the store's legitimacy, particularly its moral legitimacy, because sustainability goes beyond consumers' self-interest. In turn, store legitimacy prompts positive consumer responses (Handelman and Arnold 1999). Therefore, we hypothesize:

H2: The effects of assortment sustainability and distribution sustainability on (a) store evaluations, (b) shopping intentions, (c) word-of-mouth intentions, and (d) willingness to pay more are mediated by store legitimacy.

\section{Moderating Effects of Personal and Social Norms}

Not all consumers react to sustainability efforts similarly (Aguilera et al. 2007). Sen and Bhattacharya (2001) find, for example, that consumers who support a specific CSR domain react more positively to a company's CSR actions in that same domain. Building on two influential behavioral theories from psychology that have a prominent role in the pro-environmental behavior literature (norm-activation theory, Schwartz 1968; theory of planned behavior, Ajzen 1991), we propose that the effects of sustainability efforts on consumer responses depend on personal and social norms. Personal norms reflect feelings of moral obligation to perform specific behaviors to benefit others, according to an internalized structure of values and without regard for social or material benefits to the self (Schwartz 1977; Schwartz and Howard1980). Social norms reflect a person's perceptions of what important others think of performing a specific behavior, or "the perceived social pressure to perform or not to perform the behavior" (Ajzen 1991, p. 188). We propose that the relationship between sustainability efforts and consumer responses is strengthened by both personal and social norms favoring shopping at environmentally friendly stores, for several reasons. First, people are strongly motivated to behave consistently with their self-expectations and personal norms, because doing so results in feelings of pride, enhanced self-esteem, and other positive self-evaluations. Violations of personal norms instead spark negative self-evaluations, such as guilt or self-deprecation (Schwartz 1977). Thus, people who feel a stronger moral obligation to shop at environmentally friendly stores likely respond more positively to retail stores' sustainability efforts. Second, people have a fundamental desire to affiliate with others and behave accurately, both in order to maintain a positive self-concept. Through conforming to social norms, people seek to achieve these goals (Cialdini and Goldstein 2004). Therefore, people who perceive more social pressure to shop at environmentally friendly stores likely respond more positively to retail stores' sustainability efforts.

H3: Personal norms strengthen the effects of assortment sustainability on (a) consumers' identification with the store and (b) store legitimacy.

H4: Personal norms strengthen the effects of distribution sustainability on (a) consumers' identification with the store and (b) store legitimacy.

H5: Social norms strengthen the effects of assortment sustainability on (a) consumers' identification with the store and (b) store legitimacy.

H6: Social norms strengthen the effects of distribution sustainability on (a) consumers' identification with the store and (b) store legitimacy.

We depict our proposed conceptual model in Fig. 1. 


\section{Conceptual model}

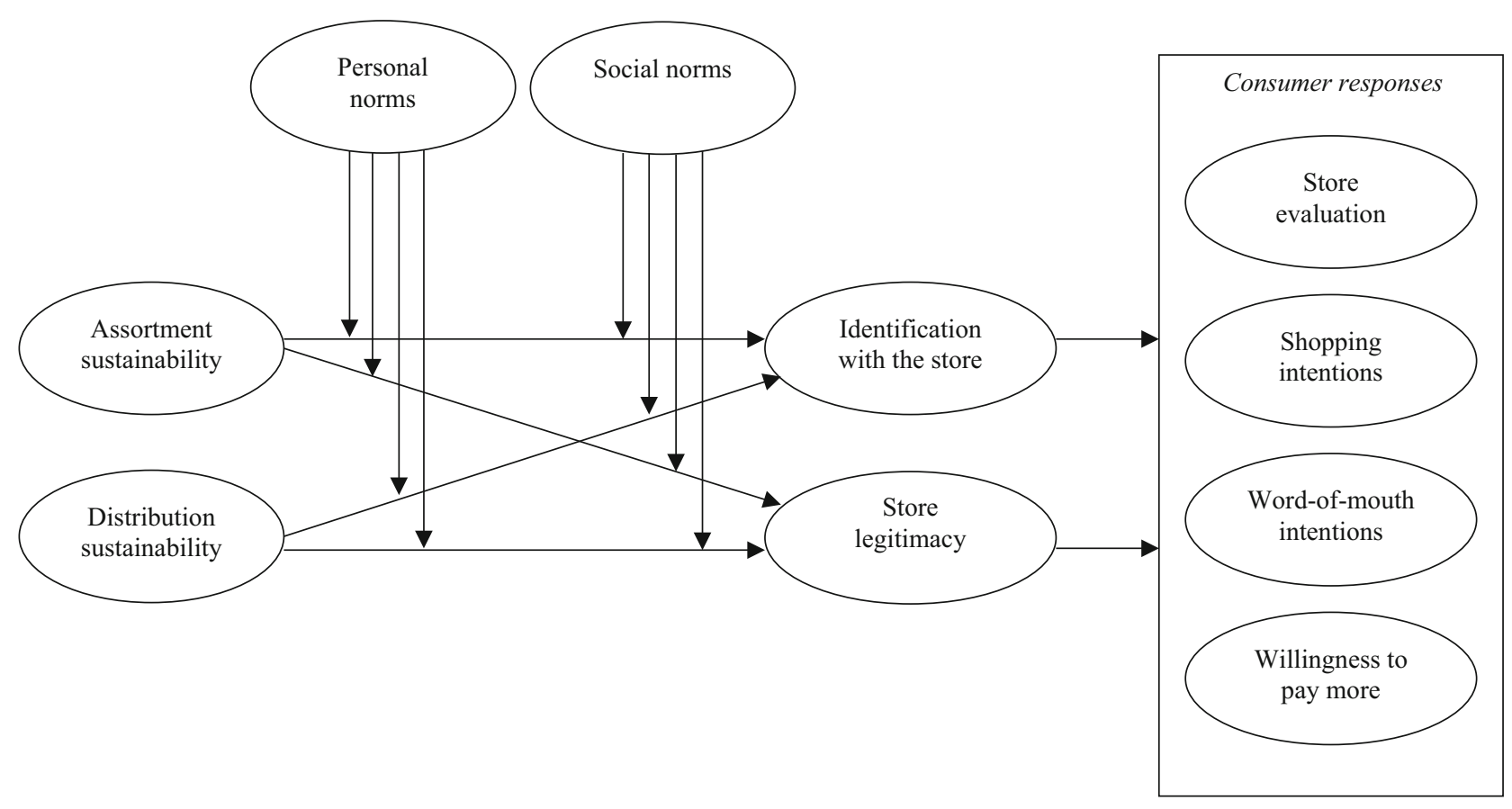

Fig. 1 Conceptual model

\section{Method}

\section{Design}

To test the hypotheses, we used a 2 (low/high assortment sustainability) $\times 2$ (low/high distribution sustainability) $\times 2$ (store type: office supplies/personal care) between-subjects design. Eight scenarios covered the different combinations of the three factors. Each scenario described a fictitious store. By including two store types, we aimed to increase the generalizability of our findings. Office supplies and personal care products clearly differ (e.g., in terms of use), but both are available in environmentally friendly versions in reality, and hence, our scenarios remained credible in both cases.

\section{Stimuli}

In the scenarios, we used real-life sustainability initiatives from the Netherlands to manipulate assortment and distribution sustainability. For assortment sustainability, we manipulated whether the store's products had an environmental quality mark (Milieukeur 2011). Products certified with the Milieukeur mark are demonstrably environmentally friendlier in their overall life cycle (from raw materials to waste) than products without the mark. For the manipulation of distribution sustainability, we described the store's participation or nonparticipation in a sustainable urban distribution initiative (Binnenstadservice). This initiative aims to reduce the amount of freight traffic in city centers in order to improve air quality, livability, and accessibility of city centers. Information about the Milieukeur mark, the Binnenstadservice initiative, and their environmental consequences appeared in the form of a newspaper article ("More stores going green"; see "Appendix 1").

Half of the scenarios depicted a fictitious store selling office supplies (OfficeSupplies), and the other half portrayed a fictitious store selling personal care products (Hair\&Care), for the store-type manipulation. Both store descriptions mentioned wide assortments, high-quality products, and affordable prices. The manipulations were checked with two manipulation check items asking: How does OfficeSupplies (Hair\&Care) score on the following two points: Environmental friendliness of the products in the assortment [very bad-very good] and environmental friendliness of the method in which they are supplied [very bad-very good].

\section{Dependent Variables, Moderators, and Mediators}

This study featured four ultimate dependent variables (store evaluation, shopping intentions, word-of-mouth intentions, and willingness to pay more), two mediators (identification and legitimacy), and two moderators (personal norms and social norms). To measure these constructs, we used existing scales and adapted them as 
necessary to fit our context. We used a double backtranslation procedure to translate the items from English to Dutch.

\section{Ultimate Dependent Variables}

We used three items to measure store evaluations, adapted from Scholder Ellen et al. (2000) (first item) and Mohr and Webb (2005) (second and third items). The three items measuring shopping intentions were also based on Mohr and Webb (2005). For word-of-mouth intentions, we used three items from Zhang and Bloemer (2008). Finally, we employed two items from Zhang and Bloemer (2008) and a third (reversed) item from Bloemer and OdekerkenSchröder (2007) to measure willingness to pay more.

\section{Mediators}

For the measure of consumers' identification with the store, we used Bergami and Bagozzi's (2000) organizational identification scale, which consists of an eight-point visual scale that assesses the degree of overlap between one's own and the organization's identity, as well as a second (nonvisual) item measured on a seven-point Likert scale. The pilot test results (coefficient $\alpha=.67, r=.50$ ) prompted the addition of a third item that we formulated as: "OfficeSupplies' (Hair\&Care's) values match my own values." In this item, we used the key component of overlap ('match') of the original two items and combined it with values, which are an important element of one's own and an organization's identity. Handelman and Arnold (1999) developed eight items to measure social as well as pragmatic legitimacy. We used the four social legitimacy items to measure store legitimacy, because we are interested in the moral aspects of legitimacy rather than the self-interest aspects (Suchman 1995) since sustainability goes beyond consumers' self-interest.

\section{Moderators}

The three items for personal norms came from Bosnjak et al. (2005). To measure social norms, we used one item from Ajzen and Madden (1986), a second item adapted from Smith et al. (2008), and a third item based on Harland et al. (1999). All items appear in Table 1, which also includes the control variable of scenario credibility (measured with two items; Sen and Bhattacharya 2001).

\section{Pilot Experiment}

We pretested our scenarios and measurement instrument among 16 consumers, who suggested wording adjustments, though they judged the scenarios as credible overall. Next, we conducted a pilot test among 130 undergraduate and graduate students. The analyses of variance (ANOVAs) revealed that the manipulations worked: For the assortment sustainability and distribution sustainability manipulations, the respective manipulation check scores were significantly higher in the high conditions than in the low conditions. The ANOVAs also revealed a few small confounding effects; the distribution sustainability manipulation significantly influenced the assortment sustainability manipulation check, and the assortment sustainability $\times$ distribution sustainability interaction significantly influenced the distribution sustainability manipulation check. However, the effect sizes $\left(\omega^{2}\right)$ were close to 0 (.00 or .01$)$ and thereby much smaller than the effect sizes of the intended manipulations, which indicated no serious confounding problems (Perdue and Summers, 1986).

Most scales performed well in terms of measurement properties. Identification had a somewhat low coefficient alpha (.67) and item correlation (.50), so we included an extra identification item in the main experiment. A low factor loading on the second social norm item led us to reformulate it.

\section{Procedure}

The main experiment included members of an Internet panel of a market research company, 2500 of whom received an invitation to participate in the study. This group was representative of the Dutch adult population in terms of age, education, and income. A cover letter stated that the study was interested in consumers' opinions about stores. People gave their informed consent before they continued. Panel members received 1 euro if they completed the study. A total of 672 people participated, resulting in a $27 \%$ response rate.

After respondents read a newspaper article and a description of the store (see "Appendix 1"), they provided their store evaluation, shopping intentions, word-of-mouth intentions, and willingness to pay more scores. They also indicated their degree of identification with the store and rated the store's legitimacy. Then they completed the manipulation check items. In the next section, they answered the personal and social norms items and indicated how familiar they were with the Milieukeur mark and Binnenstadservice initiative. They also stated whether they had bought office supplies (personal care products) in the previous 6 months. In the third section, respondents provided demographic information, and in the fourth section, they rated the scenario's credibility and believability.

\section{Sample}

The sample $(N=672)$ consisted of $43 \%$ men and $57 \%$ women. The age distribution was as follows: $18-25$ years 
Table 1 Construct items

\begin{tabular}{|c|c|}
\hline Construct items & $\begin{array}{l}\text { Factor } \\
\text { loadings }\end{array}$ \\
\hline \multicolumn{2}{|l|}{ Store evaluation $(\mathrm{CR}=.97, \mathrm{CA}=.97, \mathrm{AVE}=.93)$} \\
\hline OfficeSupplies ${ }^{\mathrm{a}}$ makes a good impression & .96 \\
\hline The impression I have of OfficeSupplies is favorable & .97 \\
\hline I have a positive image of OfficeSupplies & .97 \\
\hline \multicolumn{2}{|l|}{ Shopping intentions $(\mathrm{CR}=.93, \mathrm{CA}=.93, \mathrm{AVE}=.82)$} \\
\hline It would be very possible for me to shop at OfficeSupplies & .92 \\
\hline I would certainly shop at OfficeSupplies & .90 \\
\hline How likely would you be to shop at OfficeSupplies? [very unlikely—very likely] & .91 \\
\hline \multicolumn{2}{|l|}{ Word-of-mouth intentions $(\mathrm{CR}=.96, \mathrm{CA}=.96, \mathrm{AVE}=.89)$} \\
\hline I would say positive things about OfficeSupplies to other people & .94 \\
\hline I would recommend OfficeSupplies to people who seek my advice & .97 \\
\hline I would encourage friends and relatives to shop at OfficeSupplies & .92 \\
\hline \multicolumn{2}{|l|}{ Willingness to pay more $(\mathrm{CR}=.94, \mathrm{CA}=.94, r=.89, \mathrm{AVE}=.89)$} \\
\hline I would be willing to pay higher prices at OfficeSupplies than at other stores selling the same products & .95 \\
\hline I would be willing to continue shopping at OfficeSupplies, even if its prices increased & .94 \\
\hline $\begin{array}{l}\text { When the products I need are charged less at another store than OfficeSupplies, I would go to that other store. [reversed item, } \\
\text { deleted] }\end{array}$ & .32 \\
\hline \multicolumn{2}{|l|}{ Personal norms $(\mathrm{CR}=.94, \mathrm{CA}=.94, \mathrm{AVE}=.85)$} \\
\hline My conscience calls me to shop at environmentally friendly stores & .93 \\
\hline Shopping at environmentally friendly stores is fully in line with my moral conviction & .92 \\
\hline I feel morally obliged to shop at environmentally friendly stores & .91 \\
\hline \multicolumn{2}{|l|}{ Social norms $(\mathrm{CR}=.94, \mathrm{CA}=.95, \mathrm{AVE}=.86)$} \\
\hline Most people who are important to me think I should shop at environmentally friendly stores & .92 \\
\hline By shopping at environmentally friendly stores I would live up to the expectations that people who are important to me have & .94 \\
\hline People who are important to me would love to see me shopping at environmentally friendly stores & .92 \\
\hline \multicolumn{2}{|l|}{ Store legitimacy $(\mathrm{CR}=.91, \mathrm{CA}=.91, r=.84, \mathrm{AVE}=.84)$} \\
\hline OfficeSupplies sets an example for how other stores selling office supplies should conduct their activities. [deleted] & .93 \\
\hline OfficeSupplies is committed to meeting the standards that people expect of stores selling office supplies & .93 \\
\hline OfficeSupplies genuinely listens to the demands that people put on it & .91 \\
\hline OfficeSupplies sets an example for how other stores selling office supplies should behave. [deleted] & .94 \\
\hline \multicolumn{2}{|l|}{ Identification $(\mathrm{CR}=.88, \mathrm{CA}=.87, \mathrm{AVE}=.70)$} \\
\hline $\begin{array}{l}\text { Please indicate which case }(A, B, C, D, E, F, G \text {, or } H \text { ) best describes the level of overlap between your own and OfficeSupplies' } \\
\text { identities }\end{array}$ & .72 \\
\hline Please indicate to what degree your self-image overlaps with OfficeSupplies' image [not at all—very much] & .90 \\
\hline OfficeSupplies' values match my own values & .89 \\
\hline \multicolumn{2}{|l|}{ Scenario credibility $(\mathrm{CR}=.93, \mathrm{CA}=.93, r=.86, \mathrm{AVE}=.86)$} \\
\hline Please indicate how credible the description of OfficeSupplies was to you & .91 \\
\hline Please indicate how believable the description of OfficeSupplies was to you & .95 \\
\hline
\end{tabular}

$C R$ composite reliability, $C A$ coefficient alpha, $A V E$ average variance extracted, $r$ Pearson correlation. These reported statistics do not include the deleted items. All items were measured on seven-point Likert scales, ranging from "totally disagree" to "totally agree," unless indicated otherwise

${ }^{\text {a }}$ Half the scenarios used OfficeSupplies, the other half featured Hair\&Care

$5 \%, 26-35$ years $12 \%, 36-45$ years $15 \%, 46-55$ years $22 \%$, 56-65 years $31 \%$, and older than 65 years $15 \%$. Regarding education, $1 \%$ of the respondents finished primary education, $35 \%$ secondary education, $29 \%$ middle- level vocational education, $26 \%$ higher-level vocational education, and $9 \%$ university. Finally, $38 \%$ of the respondents reported a net household income of less than 2000 euro per month, 35\% had incomes between 2000 and 3000 
Table 2 Descriptive statistics and correlations

\begin{tabular}{llllllllllllll}
\hline Variables & Mean & SD & 1 & 2 & 3 & 4 & 5 & 6 & 7 & 8 & 9 & 10 & 11 \\
\hline 1. AS & $.01^{\text {a }}$ & 1.00 & - & & & & & & & & & \\
2. DS & .03 & 1.00 & -.03 & - & & & & & & & & \\
3. PN & 4.04 & 1.54 & .03 & .02 & $\mathbf{. 9 2}^{\mathbf{b}}$ & & & & & & & \\
4. SN & 3.28 & 1.47 & .01 & .01 & .73 &. $\mathbf{9 3}$ & & & & & & \\
5. SC & 4.42 & 1.36 & .16 & .15 & .24 & .17 & $\mathbf{. 9 3}$ & & & & & \\
6. L & 4.07 & 1.42 & .28 & .23 & .19 & .21 & .50 &. $\mathbf{9 2}$ & & & & \\
7. I & 3.48 & 1.36 & .29 & .21 & .25 & .25 & .48 & .80 & $\mathbf{. 8 4}$ & & & \\
8. SE & 4.43 & 1.47 & .33 & .31 & .10 & .11 & .46 & .74 & .77 & $\mathbf{. 9 6}$ & & \\
9. SI & 3.90 & 1.42 & .18 & .15 & .16 & .19 & .45 & .71 & .79 & .76 & $\mathbf{. 9 1}$ & & \\
10. WOM & 3.97 & 1.41 & .24 & .22 & .17 & .20 & .46 & .76 & .81 & .81 & .84 & $\mathbf{. 9 4}$ & \\
11. WPM & 2.91 & 1.46 & .22 & .15 & .35 & .40 & .34 & .59 & .67 & .54 & .64 & .65 & $\mathbf{. 9 4}$
\end{tabular}

Nonsignificant correlations $(p>.05)$ are in italics; all other correlations are significant $(p<.05) . A S$ assortment sustainability, $D S$ distribution sustainability, $P N$ personal norms, $S N$ social norms, $S C$ scenario credibility, $L$ store legitimacy, $I$ identification, $S E$ store evaluation, $S I$ shopping intentions, WOM word-ofmouth intentions, WPM willingness to pay more

${ }^{\text {a }}$ We effects-coded the categorical variables

b Numbers on the diagonal represent the square root of the AVE of each construct euro per month, and $27 \%$ reported an income of more than 3000 euro per month.

We tested for nonresponse bias using the procedure recommended by Armstrong and Overton (1977) and found no statistically significant differences in construct means for early and late respondents, indicating that the study did not suffer from a serious nonresponse bias.

\section{Measurement Properties}

To assess the validity and reliability of our measurement scales, we conducted a confirmatory factor analysis in AMOS 23. Despite a significant $\chi^{2}$ statistic $\left(\chi^{2}(324)=997.44, p<.01\right)$, the fit indices indicated a good model fit: confirmatory fit index $=.97$, TuckerLewis index $=.96$, incremental fit index $=.97$, and rootmean-squared error of approximation $=.06$. All but one of the standardized factor loadings were significant and above the recommended value of .6 (Bagozzi and Yi 1988), suggesting convergent validity (Anderson and Gerbing 1988). The factor loading of the third willingness to pay item was only .32; therefore, we deleted it. The composite reliability and coefficient alpha scores were well above the recommended values of .6 (Bagozzi and Yi 1988) and .7 (Nunnally 1978), respectively, and the average variance extracted (AVE) of each construct was greater than .5, as recommended by Fornell and Larcker (1981), in support of internal validity. We assessed discriminant validity by comparing the square root of the AVE of each construct to its correlations with the other latent constructs. The correlation between identification and store legitimacy was higher (.88) than the square root of the AVE of identification (.84).

An inspection of the items of both constructs in terms of their content prompted us to conclude that two of the four legitimacy items could be interpreted as measuring something other than perceptions of appropriateness within some socially constructed system of norms, because they could refer to perceptions of appropriateness according to each consumer's individual norms: "OfficeSupplies sets an example for how (other) stores selling office supplies should behave/conduct their activities." If someone agrees with these items, OfficeSupplies operates in line with what one finds important and thus one will likely identify with OfficeSupplies, especially if moral aspects such as sustainability are concerned. To increase the discriminant validity of both constructs, we deleted the two legitimacy items, which resulted in a square root of the AVE of identification (.84) above the correlation between identification and store legitimacy (.80), in support of discriminant validity (Fornell and Larcker 1981). For all other pairs of constructs, this criterion was also met. We provide the construct items and measurement properties in Table 1, as well as the descriptive statistics, correlations, and square roots of AVEs in Table 2.

\section{Common Method Variance}

The measures for the theoretical constructs are all selfreported measures, which are deemed appropriate because we are interested in how consumers respond to retailers' sustainability efforts in terms of their perceptions 
(identification, legitimacy), attitudes (store evaluations), intentions (shopping intentions and word-of-mouth intentions), and willingness to pay more. Furthermore, we are interested in how consumer responses to sustainability efforts are affected by their personal norms and perceived social norms. Self-reported measures may raise concerns about common method bias. We tried to reduce method bias by communicating to respondents that their answers were anonymous and that there were no right or wrong answers. According to Podsakoff et al. (2003, p. 888), "These procedures should reduce people's evaluation apprehension and make them less likely to edit their responses to be more socially desirable, lenient, acquiescent, and consistent with how they think the researcher wants them to respond." Furthermore, we pretested our questionnaire to avoid problems with ambiguous or complex items which may cause method biases (Podsakoff et al. 2003). Post hoc, we demonstrated construct validity and lack of overlap in items for different constructs as suggested by Conway and Lance (2010).

Podsakoff et al. (2003) recommend to implement statistical remedies to control for method biases, for example the single-common-method-factor approach, whereby all items load onto an unmeasured common method factor. Then, the hypothesized relationships are analyzed to see whether they remain significant. Although frequently used, Conway and Lance (2010, p. 331) see this approach as "logically indefensible as it may easily remove trait variance when multiple traits have a common cause." Richardson et al. (2009) found that this approach actually decreased the accuracy of estimated correlations compared to if no correction was applied, in cases where method variance was present and true correlations were greater than zero.

Lance et al. (2010) show that correlations between constructs measured by the same method are simultaneously attenuated due to measurement error and inflated due to common method variance. Thus, in order to obtain accurate estimates of correlations, they should be corrected for both these attenuating and inflationary effects. We adopted this approach and found that all theoretically interesting monomethod correlations (i.e., correlations in line with hypothesized effects between constructs measured by the same method) remained significant $(p<.05)$ (see "Appendix 2"), thereby providing confidence in the results we found for our structural model.

\section{Data Preparation and Hypotheses Testing Approach}

We effects-coded the categorical variables and mean-centered the continuous moderating variables before creating the interaction terms. Mean-centering served to reduce multicollinearity between the interaction terms and their composite variables; it also supported the interpretation of first-order effects of variables that were also part of interaction terms. When interactions are included (e.g., assortment sustainability $\times$ personal norms), first-order effects no longer represent main effects, but instead become conditional effects - that is, the effect of a predictor or moderator variable (e.g., assortment sustainability) on a dependent variable (e.g., store evaluation) when the other variable (personal norms) is 0 (which is equal to its mean if the variable has been mean-centered) (Aiken and West 1991).

Before we started the hypothesis testing, we determined whether the data from the two store-type contexts could be pooled, and thus, whether the measurement and structural model did not differ between contexts. Multiple-group analysis in AMOS demonstrated that the measurement weights, structural weights, structural covariances, and structural residuals were invariant across the store-type contexts, which means that we could pool the data. Then to test our hypotheses, we used structural equation modeling (SEM) in AMOS. Although SEM has been used occasionally in experimental studies, it offers important advantages over ANOVA and regression analysis (Bagozzi and Yi 1988). First, the measurement models can be represented fully by latent constructs involving multiple measurement items. Second, SEM can explicitly model measurement error, which results in greater statistical power. Third, the relationships between multiple independent and dependent constructs can be estimated simultaneously, resulting in more accurate estimates. Fourth, SEM offers not only better performance but also more convenience for mediation analyses (Iacobucci et al. 2007).

\section{Results}

\section{Manipulation Checks and the Control Variable}

The ANOVAs revealed a successful assortment sustainability manipulation $(F(1,670)=353.01, p<.01)$. The means for assortment sustainability were significantly higher in the high assortment sustainability $(\mathrm{M}=5.33)$ than in the low assortment sustainability $(M=3.20)$ conditions. The distribution sustainability manipulation was also successful $(F(1, \quad 670)=439.16, \quad p<.01$; $\left.M_{\text {high }}=5.58, M_{\text {low }}=3.06\right)$. Similar to the pilot test, we found a few, small confounding effects: The distribution sustainability manipulation significantly influenced the assortment sustainability manipulation check, and the assortment sustainability manipulation significantly affected the distribution sustainability manipulation check. However, the effect sizes $\left(\omega^{2}\right)$ were .00 and thereby much smaller than the effect sizes of the intended manipulations, 
so confounding was not a serious problem (Perdue and Summers 1986).

Overall, the participants perceived the scenarios as rather credible $(M=4.42)$; they regarded the high assortment sustainability scenarios $(M=4.64)$ as significantly more credible than the low assortment sustainability scenarios $(M=4.19 ; F(1,670)=18.74, p<.01)$. Likewise, the high distribution sustainability scenarios $(M=4.61)$ appeared more credible than the low distribution sustainability scenarios $(M=4.21 ; F(1,670)=14.82, p<.01)$. To control for the potential confounding effects of scenario credibility with sustainability manipulations, we included credibility as a covariate in our subsequent analyses (cf. Sen and Bhattacharya 2001).

\section{Model Overview}

In Table 3, we report the results for a model in which we included the two manipulations and their interaction (Model 1) (resembling an ANOVA). In Table 4, we added the first-order and interaction effects of personal and social norms (Model 2). Both models contained the hypothesized indirect paths, as well as the corresponding direct paths, as required for mediation analyses (Iacobucci et al. 2007). We used bootstrapping procedures (5000 samples) to test for the significance of indirect and total effects (Zhao et al. 2010). A nested model comparison (to compare Model 1, the constrained model, with Model 2, the full model) showed that Model 2 fit the data significantly better than Model 1.

\section{Manipulation Effects on Consumer Responses}

As expected, the results in Tables 3 and 4 show that the total effects (direct + indirect effects) of the manipulations on the consumer response variables were positive and significant $(p<.01)$. Remarkably, assortment sustainability $(b=-.17, p<.01)$ and distribution sustainability $(b=-.10, p<.05)$ had significant negative direct effects on shopping intentions when we controlled for indirect effects through identification and legitimacy. Distribution sustainability exerted a positive direct effect on store evaluations $(\mathrm{b}=.16, p<.01)$.

\section{Mediation by identification and store legitimacy}

To test for mediation, we followed Zhao et al. (2010), who recommend only one test (cf. Baron and Kenny's [1986] three-step procedure): a bootstrap test of the indirect effects. This test revealed significant indirect effects
Table 3 Model 1: effects of sustainability efforts on consumer responses

\begin{tabular}{|c|c|c|c|c|c|c|c|c|c|c|}
\hline & \multirow{2}{*}{$\begin{array}{l}I \\
D\end{array}$} & \multirow{2}{*}{$\begin{array}{l}L \\
D\end{array}$} & \multicolumn{2}{|l|}{ SE } & \multicolumn{2}{|l|}{ SI } & \multicolumn{2}{|l|}{ WOM } & \multicolumn{2}{|l|}{ WPM } \\
\hline & & & $D$ & $I$ & $D$ & $I$ & $D$ & $I$ & $D$ & $I$ \\
\hline \multicolumn{11}{|c|}{ First-order effects } \\
\hline $\mathrm{SC}$ & $.25 * *$ & $.51 * *$ & -.02 & $.45 * *$ & -.03 & $.50 * *$ & -.04 & $.48 * *$ & -.06 & $.41 * *$ \\
\hline AS & $.16^{* *}$ & $.30 * *$ & $.11 * *$ & $.27 * *$ & $-.15 * *$ & $.31 * *$ & -.06 & $.29 * *$ & .01 & $.25 * *$ \\
\hline DS & $.11 * *$ & $.24 * *$ & $.18 * *$ & $.20 * *$ & $-.09 *$ & $.22 * *$ & .01 & $.21 * *$ & -.01 & $.18^{* *}$ \\
\hline \multicolumn{11}{|l|}{ PN } \\
\hline \multicolumn{11}{|l|}{$\mathrm{SN}$} \\
\hline$I$ & & & $1.24 * *$ & & $1.54 * *$ & & $1.36 * *$ & & $1.23 * *$ & \\
\hline$L$ & & & $.28 * *$ & & $.22 * *$ & & $.26 * *$ & & $.20 * *$ & \\
\hline \multicolumn{11}{|c|}{ Interaction effects } \\
\hline $\mathrm{AS} \times \mathrm{DS}$ & .01 & -.07 & -.01 & -.01 & -.01 & -.01 & .01 & -.01 & .05 & -.01 \\
\hline \multicolumn{11}{|l|}{$\mathrm{AS} \times \mathrm{PN}$} \\
\hline \multicolumn{11}{|l|}{$\mathrm{DS} \times \mathrm{PN}$} \\
\hline \multicolumn{11}{|l|}{$\mathrm{AS} \times \mathrm{SN}$} \\
\hline \multicolumn{11}{|l|}{$\mathrm{DS} \times \mathrm{SN}$} \\
\hline$R^{2}$ & .36 & .36 & & .70 & & .74 & & .77 & & .45 \\
\hline$\chi^{2}$ & \multicolumn{10}{|c|}{$2191.43 * *$} \\
\hline$d f$ & \multicolumn{10}{|l|}{645} \\
\hline Fit indices & \multicolumn{10}{|c|}{$\mathrm{CFI}=.94, \mathrm{TLI}=.94, \mathrm{IFI}=.95, \mathrm{RMSEA}=.06$} \\
\hline
\end{tabular}

$S C$ scenario credibility, $A S$ assortment sustainability, $D S$ distribution sustainability, $P N$ personal norms, $S N$ social norms, $I$ identification, $L$ store legitimacy, $S E$ store evaluation, $S I$ shopping intentions, WOM wordof-mouth intentions, $W P M$ willingness to pay more. $D$ direct effects, $I$ indirect effects. When both direct and indirect effects are involved, significant total effects $(p<.05)$ are highlighted in bold

$* p<.05 ; * * p<.01$ (two-tailed). Estimates are unstandardized estimates 
Table 4 Model 2: effects of sustainability efforts on consumer responses including interactions

\begin{tabular}{|c|c|c|c|c|c|c|c|c|c|c|}
\hline & \multirow{2}{*}{$\begin{array}{l}I \\
D\end{array}$} & \multirow{2}{*}{$\frac{L}{D}$} & \multicolumn{2}{|l|}{ SE } & \multicolumn{2}{|l|}{ SI } & \multicolumn{2}{|l|}{ WOM } & \multicolumn{2}{|l|}{ WPM } \\
\hline & & & $D$ & $I$ & $D$ & $I$ & $D$ & $I$ & $D$ & $I$ \\
\hline \multicolumn{11}{|c|}{ First-order effects } \\
\hline $\mathrm{SC}$ & $.22 * *$ & $.46^{* *}$ & -.01 & $.43 * *$ & -.03 &. $\mathbf{4 5} * *$ & -.04 &. $\mathbf{4 4} * *$ & -.09 & $.34 * *$ \\
\hline AS & $.16^{* * *}$ & $.31 * *$ & .08 & $.31 * *$ & $-.17 * *$ &. $\mathbf{3 3} * *$ & -.08 & $.32 * *$ & .02 & $.25 * *$ \\
\hline DS & $.11 * *$ & $.23 * *$ & $.16^{* *}$ & $.21 * *$ & $-.10 *$ & $.22 * *$ & -.00 & $.21 * *$ & -.00 & $.17 * *$ \\
\hline PN & -.01 & -.07 & -.06 & -.03 & -.07 & -.02 & -.05 & -.03 & .05 & -.02 \\
\hline SN & $.11 * *$ & $.21 * *$ & -.09 & $.21 * *$ & -.01 & $.22 * *$ & -.02 & $.21 * *$ & $.19 * *$ & $.17 * *$ \\
\hline$I$ & & & $1.40 * *$ & & $1.64 * *$ & & $1.46 * *$ & & $1.21 * *$ & \\
\hline$L$ & & & $.28 * *$ & & $.21 * *$ & & $.26 * *$ & & $.18 * *$ & \\
\hline \multicolumn{11}{|c|}{ Interaction effects } \\
\hline $\mathrm{AS} \times \mathrm{DS}$ & -.01 & -.09 & .00 & -.04 & -.00 & -.03 & .02 & -.03 & .04 & -.03 \\
\hline $\mathrm{AS} \times \mathrm{PN}$ & $.21 * *$ & $.33 * *$ & $-.12 *$ & $.38 * *$ & -.06 &. $\mathbf{4 0} * *$ & -.09 & $.38 * *$ & -.06 &. $\mathbf{3 1} * *$ \\
\hline $\mathrm{DS} \times \mathrm{PN}$ & $.10^{* * *}$ & .12 & -.02 &. $\mathbf{1 8} * *$ & -.01 & $.19 * *$ & .02 & $.18 * *$ & -.03 & $.15^{* *}$ \\
\hline $\mathrm{AS} \times \mathrm{SN}$ & $-.13 * *$ & $-.19 * *$ & .06 & $-.23 * *$ & .05 & $-.25 * *$ & .07 & $-.24 * *$ & .02 & $-.19 * *$ \\
\hline $\mathrm{DS} \times \mathrm{SN}$ & $-.06^{*}$ & -.09 & -.01 & -.11 & .04 & -.11 & -.01 & -.11 & -.02 & -.09 \\
\hline$R^{2}$ & .49 & .43 & & .73 & & .76 & & .79 & & .54 \\
\hline$\chi^{2}$ & \multicolumn{10}{|l|}{$1915.57 * *$} \\
\hline$d f$ & \multicolumn{10}{|l|}{609} \\
\hline$\Delta \chi^{2}(\Delta d f)$ & \multicolumn{10}{|c|}{$\Delta \chi^{2}(36)=275.86^{* *}(\mathrm{cf}$. Model 1$)$} \\
\hline Fit indices & \multicolumn{10}{|c|}{$\mathrm{CFI}=.95, \mathrm{TLI}=.94, \mathrm{IFI}=.95, \mathrm{RMSEA}=.06$} \\
\hline
\end{tabular}

$S C$ scenario credibility, $A S$ assortment sustainability, $D S$ distribution sustainability, $P N$ personal norms, $S N$ social norms, $I$ identification, $L$ store legitimacy, $S E$ store evaluation, $S I$ shopping intentions, WOM word-of-mouth intentions, WPM willingness to pay more. $D$ direct effects, $I$ indirect effects. When both direct and indirect effects are involved, significant total effects $(p<.05)$ are highlighted in bold

$* p<.05 ; * * p<.01$ (two-tailed). Estimates are unstandardized estimates

$(p<.01)$ of assortment sustainability and distribution sustainability on consumers' store evaluations, shopping intentions, word-of-mouth intentions, and willingness to pay more. For these effects, mediation thus occurred by identification and store legitimacy together. To determine whether each of the mediators also mediated the relationships, we turned to the Sobel $z$ test, because the bootstrapping procedure in AMOS does not provide confidence intervals for separate indirect effects through multiple mediators (Iacobucci et al. 2007).

We predicted in $\mathrm{H} 1$ that the effects of assortment sustainability and distribution sustainability on consumer responses would be mediated by identification. $\mathrm{H} 1$ received confirmation from the Sobel $z$ test results (all $z$ values $>2.58$, which indicated that the indirect effects were significant at $p<.01)$. H2, which predicted that the effects of both sustainability efforts would be mediated by store legitimacy, was also supported by the Sobel $z$ test (all $z$ values $>2.58$ ). The estimates of the indirect effects of both sustainability efforts on consumer responses showed stronger effects through identification than through store legitimacy.

Using nested model comparisons, we compared the full model (containing both mediators) with two constrained models (in which the paths to and from one of the mediators equaled 0$)$. The full model $\left(\chi^{2}(609)=1915.57\right.$, $p<.01)$ fit the data significantly better than either a store legitimacy-only $\left(\Delta \chi^{2}(14)=600.86, p<.01\right)$ or identification-only $\left(\Delta \chi^{2}(15)=376.94, p<.01\right)$ model, which indicated that the two routes are indeed complementary. These findings also showed that the identification-only model performed better than the legitimacy-only model, which underlined the finding that the route via identification is the stronger route from sustainability efforts to consumer responses.

\section{Moderating Effects of Personal and Social Norms}

In $\mathrm{H} 3$ and $\mathrm{H} 4$, we stated that personal norms would strengthen the effects of assortment and distribution sustainability on consumers' identification with the store and store legitimacy. We found support for the positive interaction effect between personal norms and assortment sustainability on identification $(b=.21, \quad p<.01)$ and legitimacy $(b=.33, p<.01)\left(\mathrm{H}_{3}\right)$. Also, the effect of distribution sustainability on identification was strengthened by personal norms ( $b=.10, p<.01$; H4a), but not the effect on legitimacy $(b=.12, p>.05 ; \mathrm{H} 4 \mathrm{~b})$ (see Fig. 2, Panels A and B). 

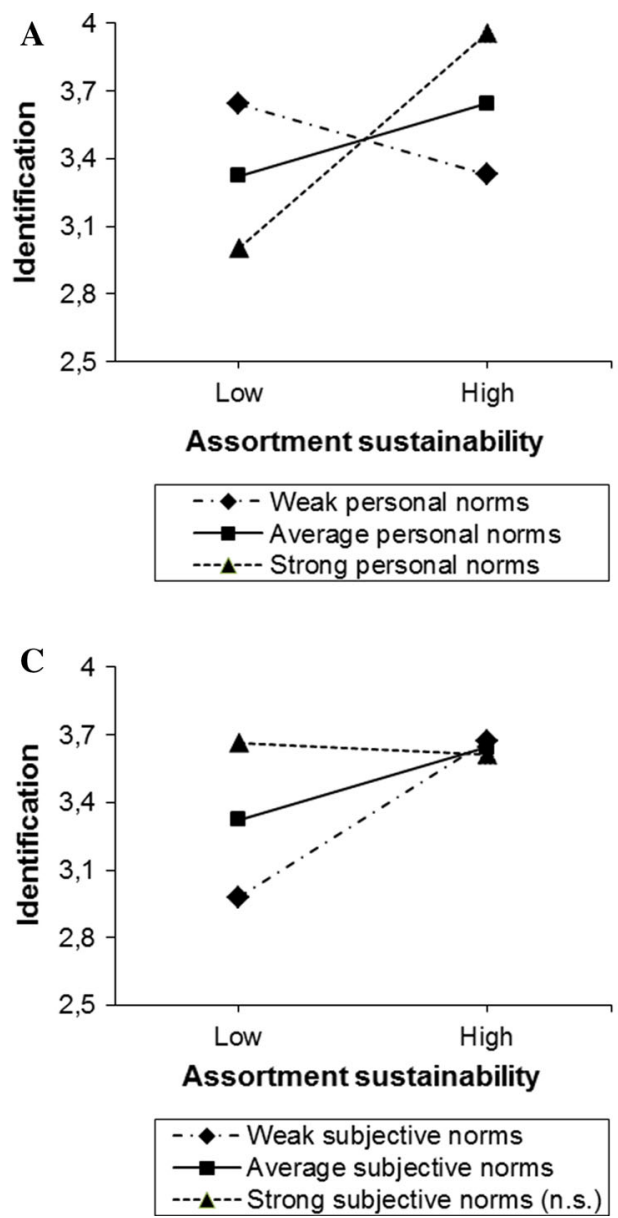

Fig. 2 Illustration of interaction effects. a Interaction effect of assortment sustainability and personal norms (When controlling for the interaction effect of assortment sustainability and social norms.). b Interaction effect of distribution sustainability and personal norms (When controlling for the interaction effect of distribution sustainability and social norms.). c Interaction effect of assortment sustainability and social norms (When controlling for the interaction effect of assortment sustainability and personal norms.). d Interaction

In contrast to H5, when controlling for moderation by personal norms, social norms weakened (rather than strengthened) the effects of assortment sustainability on consumers' identification with the store $(b=-.13$, $p<.01)$ and store legitimacy $(b=-.19, p<.01)$. The interaction between social norms and distribution sustainability on identification was also negative and significant $(b=-.06, p<.05)$, whereas the effect on legitimacy was not significant $(b=-.09, p>.05)$. That is, we did not find support for H6 (see Fig. 2, Panels C and D). ${ }^{2}$

\footnotetext{
${ }^{2}$ We also tested our hypotheses using regression analysis and the PROCESS macro (Hayes, version 2.16; Hayes 2012, 2013-2015) and found the same results (in terms of significance and sign of the effects), except for the (negative) interaction effect of distribution
}
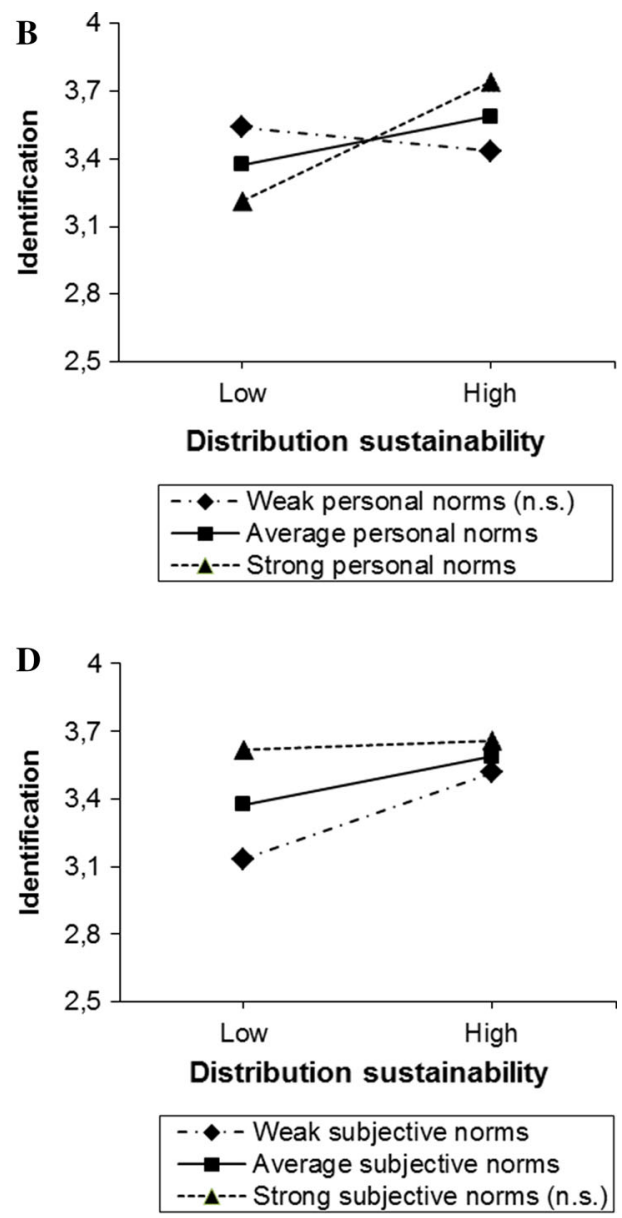

effect of distribution sustainability and social norms (When controlling for the interaction effect of distribution sustainability and personal norms.). Notes n.s. slope is not significantly different from zero. We display the interaction effects on consumers' identification with the store. For store legitimacy, the effects have comparable patterns (significance and slope direction); the magnitudes of the slopes of the interaction effects and the absolute predicted values for legitimacy are different

\section{Discussion}

\section{Theoretical Implications}

This study has aimed to contribute to an improved understanding of how and when retailers' sustainability efforts translate into positive consumer responses. To that end, we examined personal and social mechanisms underlying consumer responses to retail stores' sustainability efforts and thereby responded to calls for research, as issued by Bhattacharya et al. (2009), Yoon et al. (2006) and Vitell (2015). Our mediation and moderation analyses showed

Footnote 2 continued sustainability $\times$ social norms on identification, which failed to reach significance. 
several interesting findings, which extend prior research and advance the marketing literature.

Our mediation analyses showed that consumers' positive responses to retailers' sustainability efforts largely occur through two routes: a personal route, via consumers' identification with the retail store, and a social route, through store legitimacy. These routes are complementary, which implies that future research on consumer responses to sustainability efforts should consider both mechanisms simultaneously instead of just one or the other, which has been the case in prior studies (Handelman and Arnold 1999; Lichtenstein et al. 2004; Sen and Bhattacharya 2001). The two routes encompass benefits at different levels: the consumer level and retailer level. Retailers' sustainability efforts as such may directly benefit consumers (and society at large), for example by minimizing exhaust emissions in city centers. In addition, our findings suggest that retailers' sustainability efforts enable consumers to identify with retailers. Such a perception to be one with or belong to an organization that does good can trigger positive psychological effects, because it contributes to consumers' self-esteem by allowing them to define themselves as people who do good (Ashforth and Mael 1989; Bergami and Bagozzi 2000). Hence, retailers' sustainability efforts may have positive effects, both physical and psychological, on consumer well-being.

The route via store legitimacy shows that retailers that make sustainability efforts are perceived as acting in line with institutional norms, which, according to institutional theory, is crucial for organizational survival (Meyer and Rowan 1977). Without legitimacy, organizations are unable to obtain the necessary support from stakeholders, including investors, customers, and employees (Zimmerman and Zeitz 2002). Therefore, legitimacy is of direct benefit to the retailer.

We found that the personal route through identification led to much stronger effects of sustainability efforts on consumer responses than the social route via legitimacy, which highlights the important role personal factors play in consumer responses to sustainability efforts. A similar pattern of results occurred for both assortment sustainability and distribution sustainability. However, as suggested by Peloza and Shang (2011), different sustainability efforts might have differential effects. We suggest that future research on consumer responses to sustainability efforts examines potential differences not only in ultimate outcomes of sustainability efforts, but also in the mechanisms that lead to those outcomes. Some efforts might exert their influence more strongly through the personal route, whereas others might largely follow the social route. In addition, these routes might interact.
After controlling for the indirect (positive) effects of sustainability efforts on consumer responses via identification and legitimacy, we also detected some direct effects that remained. Baron and Kenny (1986, p. 1176) note that such direct effects indicate "the operation of multiple mediating factors," and Zhao et al. (2010, p. 199) contend that "such direct paths often result from omission of one or more mediators from the model" and that "the sign of the mysterious 'direct' effect has heuristic value for theory building." The sign of a remaining direct effect indicates which sign the additional mediator should have, but we found both positive and negative remaining direct effects. Therefore, it appears that at least two additional mediators are operating, one with a positive sign and another with a negative sign. Existing research suggests that customer satisfaction (Luo and Bhattacharya 2006) or perceived value (Peloza and Shang 2011) might be potential positive mediators of the sustainability efforts-consumer responses relationship; consumer skepticism might be a likely negative mediator. The number of companies that claim to operate in a socially responsible or sustainable way has increased dramatically in the past two decades (e.g., Adweek 2009), while incidents of irresponsible behaviors such as greenwashing simultaneously have rendered consumers skeptical of such claims (Cronin et al. 2011; Mohr et al. 1998; Wagner et al. 2009). Alternatively, consumers' perceived organizational motives (i.e., attributions) might be potential positive and negative mediators of the sustainability efforts-consumer responses relationship. Sustainability efforts might induce both positive (valuesdriven and strategic-driven) attributions and negative (stakeholder-driven) attributions, which in turn affect consumer responses such as purchase intentions (Groza et al. 2011).

In addition to how sustainability efforts translate into positive consumer responses, we also examined when it occurs, i.e., under which conditions. We expected that consumers' positive responses would be enhanced by two conditions, namely if consumers (1) had strong personal norms and (2) felt strong social norms, both in favor of shopping at environmentally friendly stores. The effects of personal norms were as hypothesized, except for the interaction effect of distribution sustainability and personal norms on store legitimacy, which was not significant. Figure 2, Panels A and B show that consumers with weak personal norms do not respond or even respond negatively in terms of identification (and legitimacy) to retailers' sustainability efforts, whereas consumers with average or strong personal norms respond positively. These findings contribute to an improved understanding of the boundaries and opportunities of sustainability efforts. 
Remarkably, the effects of social norms were opposite to what we expected: When we controlled for moderation by personal norms, the effects of assortment sustainability on identification and legitimacy, and the effect of distribution sustainability on identification were weakened by social norms. This result contradicts most prior research on social norms (e.g., Goldstein et al. 2008; Smith et al. 2008); reactance theory may provide an explanation. That is, people believe that they have behavioral freedoms (Brehm and Mann 1975; Woller et al. 2007), such as the freedom to respond to sustainability efforts as they prefer. When this freedom appears threatened, such as by social pressure to perform a certain behavior (beyond the person's personal norms), it may invoke feelings of reactance, "a motivational state that is directed toward the restoration of whatever freedom has been threatened or eliminated" (Brehm and Mann 1975, p. 816). Threatened freedom can be restored by resistance to social pressure.

In the context of our study, social pressure to shop at environmentally friendly stores may arouse reactance and cause consumers to respond less positively or not respond at all in terms of identification and legitimacy to retailers' sustainability efforts. The dramatic increase in attention to sustainability in recent years may have created sustainability overkill: Our findings suggest that consumers do not want to be told that they should shop at environmentally friendly stores. Instead, they seem to prefer to decide for themselves how to behave, which is in line with our finding that personal norms strengthen the effects of sustainability efforts on identification and legitimacy. These results imply that the role of the social environment in consumer responses to sustainability efforts may diverge from prevailing views on the effect of social milieu on consumer behavior (e.g., Ajzen 1991).

\section{Managerial Implications}

We demonstrate that retailers with a sustainable assortment and a sustainable distribution achieve more positive store evaluations, stronger shopping intentions and word-ofmouth intentions, and a higher willingness to pay more by consumers than retailers that do not have a sustainable assortment or distribution. These findings show that traditional marketing mix elements provide opportunities for retailers to improve their organizations' bottom line and positively affect consumer and societal well-being. For example, the Binnenstadservice initiative aims to reduce the amount of freight traffic in city centers by consolidating goods from multiple retailers in a distribution center outside the city center. Instead of multiple suppliers entering the city center with small shipments, only the Binnenstadservice truck enters the city center to distribute the goods, which leads to promising results in terms of reduced inconvenience for residents, improved traffic safety, and a more attractive shopping environment (Van Rooijen and Quak 2010). By participating in the Binnenstadservice initiative, retailers have the potential to improve the quality of life of city center residents and shoppers and to distinguish themselves from retailers that do not participate (until the point that all retailers participate). Furthermore, sustainability efforts allow consumers to identify with retailers that do good, which likely contributes to their self-esteem. It thus may pay off for retailers to make consumers aware of their sustainability efforts. Retailers might highlight their sustainable products and business practices through company websites and in-store information displays, though research suggests that their communication strategies must take care to avoid consumer perceptions of company hypocrisy (Wagner et al. 2009) or insincere motives (Yoon et al. 2006). Our study shows that the effects of retailers' sustainability efforts on consumer responses are mediated by consumers' identification with the store and store legitimacy. In addition to the positive consequences of identification and legitimacy on store evaluations, shopping intentions, word-of-mouth intentions, and willingness to pay more, these concepts might have other positive effects. Morgan and Hunt (1994), for example, show (in a businessto-business context) that shared values, which are the basis for organizational identification, improve customer trust and relationship commitment, which in turn lead to a range of positive outcomes. Sustainability efforts that improve organizational identification may provide retailers with the opportunity to build relationships with their customers. In addition, these efforts contribute to an organization's legitimacy, which is crucial for organizational survival (Zimmerman and Zeitz 2002).

The effects of sustainability efforts on consumer responses grow stronger due to personal norms; when we controlled for such norms, the effects were weakened by social norms. Therefore, managers must take care with the message in their sustainability communications. In trying to convince consumers to shop at sustainable stores, retailers should avoid referring to norms held by important others (e.g., "Don't you think your friends would want you to shop responsibly?") and focus instead on consumers' personal norms. Consumers are motivated to behave consistently with their personal norms, because doing so results in positive self-evaluations, such as pride or self-esteem (Schwartz 1977). By emphasizing positive self-evaluations (e.g., "Shop with pride. Shop responsibly"), retailers can activate personal norms and prompt more favorable consumer responses to sustainability efforts. In addition, the insights of this study can help retailers decide whether or not to invest in and communicate about sustainability. For example, if a retailer knows that its target customers have weak personal norms regarding shopping at environmentally friendly stores, it may decide 
not to invest in sustainability or at least not to actively communicate about it to its customers, because they tend to respond negatively.

Although from a marketing perspective it is clear that the implications above can benefit retailers, from an ethical perspective the question can be asked whether informing companies how they can manipulate consumer behavior in order to increase the effectiveness of their sustainability efforts is ethical. According to Beauchamp's (2001, cited by Villarán 2015) "continuum of influences", companies can use advertising in three ways to make people buy a product, or in this case shop at sustainable stores: by using rational persuasion, coercion, or manipulation. Manipulative advertising in turn can be divided into deceptive and irrational advertising (Villarán 2015). It is generally agreed upon that advertising should not be deceptive, i.e., bringing about consumer misconceptions using false claims, important omissions, or misrepresentations of what the facts mean (Sher 2011). However, irrational advertising (playing on people's vulnerabilities instead of their reason) is different: It is not illegal, commonly used, and accepted by many (Villarán 2015). Still, irrational advertising can be criticized.

Most importantly, irrational advertising threatens people's moral autonomy as theorized by Kant. Kant (1999[1788], cited by Villarán 2015, p. 7), defines autonomy of the will as "the sole principle of all moral laws and duties in keeping with them... That is to say, the sole principle of morality consists in independence from all matter of the law (namely, from a desired object) and at the same time in the determination of choice through the mere form of giving universal law that a maxim must be capable of." Accordingly, the critique on irrational advertising can be described as "to manipulate people is not to treat them as ends-certainly not as autonomous legislating members of a kingdom of ends. (...) it is something that we prefer not to happen to us and therefore shall not will it as a universal maxim" (Hare 1984, p. 28). So even if the goal of irrational advertising is to increase sustainable consumer behavior and sustainability is generally regarded as something positive, the action of manipulating consumers is wrong in itself, regardless of its consequences ${ }^{3}$ (Villarán

\footnotetext{
3 Villarán (2015, p. 1) notes that "irrational advertising not only entails treating humanity merely as means, but it also threatens moral autonomy by encouraging heteronomy and sometimes even a rebellion against the moral law." If the goal of irrational advertising is to increase sustainable consumer behavior, it may not encourage heteronomy, or "capitulating to lawless happiness" (Villarán 2015, p. 8). On the contrary, consumers are asked to go beyond self-interest. However, our findings suggest that in the presence of strong social norms to behave sustainably, the outcome might still be a rebellion against the moral law in the sense that consumers might develop feelings of reactance and as a consequence might not behave sustainably although it is the right thing to do from a moral perspective.
}

2015). The same applies to informing companies how they can manipulate consumers by appealing to social or personal norms: the end does not justify the means.

However, not all advertising is wrong in the sense that it threatens moral autonomy. If we recall Beauchamp's "continuum of influences," the positive extreme of the continuum consists of rational persuasion: "A deliberative and successful attempt by one person to encourage another to freely accept beliefs, attitudes, values, or actions through appeals to reason" (Beauchamp 2001, p. 477, cited by Villarán 2015 , p. 2). So instead of appealing to personal norms, retailers could use rational advertising to inform consumers about the consequences of shopping at sustainable stores. For example, the factual effects of a sustainable assortment compared to an unsustainable assortment on the environment can be advertised. Such advertising could increase consumers' awareness of consequences, which in turn might influence consumer behavior as well as consumers' personal norms. The difference is that this influence is now based on appeals to reason instead of people's vulnerabilities.

Finally, the question can be asked whether it is commercial companies' responsibility to change consumer behavior, in this case, to persuade consumers to make shopping decisions based on sustainability. We argue that this is not necessarily companies' responsibility, but as Vitell (2015) shows, for Corporate Social Responsibility to be successful, Consumer Social Responsibility is required. So it will lead to commercial success if companies can convince consumers to shop based on sustainability. In fact, one could go even one step further and argue that it is indeed CSR-focused companies' responsibility to convince consumers to make shopping decisions based on social responsibility/sustainability, because only then they can maximize their beneficial impact on society.

\section{Limitations and Suggestions for Further Research}

With our experimental approach, we manipulated two specific sustainability efforts in the context of two store types and gathered deeper insights into how and when retailers' sustainability efforts translate into positive consumer responses. However, there are also several limitations inherent to our method, which offer suggestions for further research.

First, we used a scenario-based approach, which limits the external validity of our findings. Although we tried to make the scenarios as credible and realistic as possible, scenarios are always simplified, limited versions of reality. Most consumers probably take into account various store attributes, such as store atmosphere and friendliness of store personnel, beyond sustainability, when evaluating a retailer and choosing where to shop (Pan and Zinkhan 
2006). Furthermore, actual consumer awareness of companies' sustainability efforts is generally low, which hinders companies' abilities to reap rewards from their efforts (Sen et al. 2006). To increase external validity, further research should examine consumer responses to sustainability efforts implemented by a real company in a real-life situation. In addition, the effects of consumer awareness of and familiarity with companies' sustainability efforts, as well as the influence of consumers' sociodemographic characteristics on consumer responses to sustainability efforts, should be investigated.

Second, though our research provides a nuanced view of consumer responses to retailers' sustainability efforts, we measured behavioral intentions (shopping intentions, wordof-mouth intentions, and willingness to pay more) instead of actual behavior. Intentions do not automatically translate into behavior (Ajzen 1991). For example, many consumers say they are willing to buy green products, but only a small percentage of consumers do so (Luchs et al. 2010). Therefore, additional research should focus on actual behavior.

Third, two of the four legitimacy scale items were deleted during the evaluation of our measurement model. Although this step was necessary to obtain discriminant validity of the legitimacy and identification constructs, the question might arise whether the meaning of the legitimacy scale has changed. In order to arrive at the decision to delete two items, we carefully looked at the definition of the construct and concluded that these two items could be interpreted as measuring something other than perceptions of appropriateness within some socially constructed system of norms. So by deleting these items, we believe that the scale better reflects the legitimacy construct as we defined it in our study (with a focus on the moral aspects of legitimacy). However, two-item scales might pose problems in terms of not representing the entire content domain of the construct (MacKenzie et al. 2011). Therefore, we do suggest further research on the conceptual definition of legitimacy and its measurement (including formal scale development procedures, see, e.g., MacKenzie et al. 2011), in particular in the context of sustainability, because it influences the extent to which the pragmatic and moral components of legitimacy are relevant.

Fourth, our findings suggest the need to examine additional mediators (both positive and negative) to explain the direct effects of sustainability efforts on consumer responses. Potential positive mediators include customer satisfaction (Luo and Bhattacharya 2006), perceived value (Peloza and Shang 2011) or positive (values-driven or strategic-driven) attributions (Groza et al. 2011); negative mediators might be consumer skepticism (Cronin et al. 2011; Mohr et al. 1998; Wagner et al. 2009) or negative (stakeholder-driven) attributions (Groza et al. 2011). It would also be interesting to test reactance theory as a potential explanation for our finding that (when controlling for moderation by personal norms) subjective norms negatively moderate the effects of store assortment sustainability on consumer responses.

\section{Compliance with Ethical Standards}

Conflict of interest The authors declare that they have no conflict of interest.

Open Access This article is distributed under the terms of the Creative Commons Attribution 4.0 International License (http://crea tivecommons.org/licenses/by/4.0/), which permits unrestricted use, distribution, and reproduction in any medium, provided you give appropriate credit to the original author(s) and the source, provide a link to the Creative Commons license, and indicate if changes were made.

\section{Appendix 1}

\section{Newspaper Article and Manipulations}

Please imagine the following situation (the store that is mentioned [OfficeSupplies] does not exist in reality; Milieukeur and Binnenstadservice do exist in reality):

You would like to buy office supplies (e.g., paper, pens, a stapler). OfficeSupplies is a store selling those products. Recently, you read the following newspaper article: 


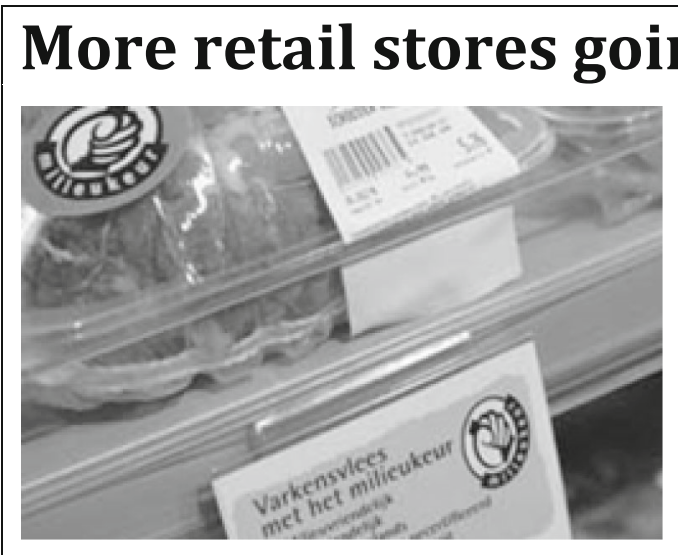

An increasing number of retail stores have products with the Milieukeur mark in their assortments.

More and more retail stores are going green. This has been concluded in a large scale academic study among more than 5,000 stores in different municipalities in the Netherlands. The number of stores having products with the Milieukeur mark in their assortments is increasing. Products certified with the Milieukeur mark are demonstrably environmentally friendlier in their overall life cycle (e.g., raw materials, production, packaging, and waste) than other products of the same sort. The Milieukeur mark can be awarded to different kinds of products. Certification is executed by professional, independent certification institutes which follow the European product certification norms.
In addition, more and more retail stores try to make their distribution environmentally friendlier. An example is the recent establishment of Binnenstadservice in several cities in the Netherlands. In those cities, stores located in the city center can become participants in Binnenstadservice. This means that goods for those stores are no longer delivered to the stores, but to a terminal just outside the city center. Goods destined for multiple stores get consolidated and then delivered to stores in the city center by a relatively clean truck (operating on natural gas). Numerous stores in city centers receive many small shipments from different suppliers. By consolidating shipments Binnenstadservice aims to reduce the amount of freight traffic and improve the air quality in city centers.

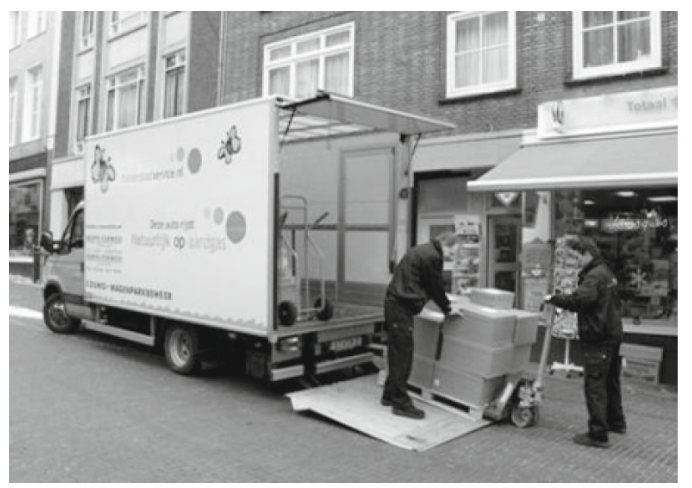

An increasing number of retail stores participate in Binnenstadservice.

Manipulations

General information

OfficeSupplies has a wide assortment of high-quality office supplies. Prices are affordable.

Low assortment sustainability

None of the products in the assortment of OfficeSupplies has the Milieukeur mark. A Milieukeur employee explains: "The products in the assortment of OfficeSupplies are far from meeting the requirements for receiving the Milieukeur mark."

Low distribution sustainability

OfficeSupplies does not participate in Binnenstadservice. Birgit Hendriks, founder of Binnenstadservice, explains: "Because OfficeSupplies does not participate in Binnenstadservice, up to five trucks (from different suppliers) visit their store each day rather than one (from Binnenstadservice), resulting in much more exhaust gases!"
High assortment sustainability

All products in the assortment of OfficeSupplies have the Milieukeur mark. A Milieukeur employee explains: "The products in the assortment of OfficeSupplies clearly meet the requirements for receiving the Milieukeur mark."

High distribution sustainability

OfficeSupplies participates in Binnenstadservice. Birgit Hendriks, founder of Binnenstadservice, explains: "Because OfficeSupplies participates in Binnenstadservice, only one truck (from Binnenstadservice) rather than five trucks (from different suppliers) visit their store each day, resulting in much less exhaust gases!" 


\section{Appendix 2}

\section{Correction for Attenuation and Method Effects for Monomethod Correlations}

We adopted the procedure suggested by Lance et al. (2010) to simultaneously correct for attenuation due to unreliability and inflation due to common method variance:

$\hat{\rho}_{X_{i j} X_{i^{\prime} j}}=\frac{r_{X_{i j} X_{i^{\prime} j}}-\lambda_{M_{i j}} \lambda_{M_{i^{\prime} j}}}{\lambda_{T_{i j}} \lambda_{T_{i^{\prime} j}}}$

where the $\rho$ s represent the disattenuated and method variance-adjusted correlations, the $r$ s are the corresponding observed correlations, $\lambda_{\mathrm{M}} \mathrm{s}$ are the effects of measurement methods on observed measures, and $\lambda_{\mathrm{T}} \mathrm{s}$ are reliability indexes (square roots of reliability coefficients). For the $\lambda_{\mathrm{T}} \mathrm{s}$, we used the square roots of composite reliability scores. For the $\lambda_{\mathrm{M}} \mathrm{s}$, we used the mean of all mean CFAestimated method factor loadings reviewed by Lance et al. (2010, Table 2, p. 446), which is .427 . The resulting corrected correlation matrix for monomethod correlations is:

\begin{tabular}{llllllllll}
\hline Variables & 1 & 2 & 3 & 4 & 5 & 6 & 7 & 8 & 9 \\
\hline 1. PN & - & & & & & & & \\
2. SN & .58 & - & & & & & & \\
3. SC & .06 & .00 & - & & & & & \\
4. L & .01 & .03 & .35 & - & & & & & \\
5. I & .07 & .07 & .33 & .69 & - & & & \\
6. SE & .00 & .00 & .29 & .59 & .64 & - & & & \\
7. SI & .00 & .01 & .29 & .57 & .67 & .61 & - & & \\
8. WOM & .00 & .02 & .29 & .62 & .68 & .65 & .70 & - & \\
9. WPM & .18 & .23 & .17 & .44 & .54 & .37 & .49 & .49 & - \\
\hline
\end{tabular}

Nonsignificant correlations $(p>.05)$ are in italics; all other correlations are significant $(p<.05) . P N$ personal norms, $S N$ social norms, $S C$ scenario credibility, $L$ store legitimacy, $I$ identification, $S E$ store evaluation, $S I$ shopping intentions, WOM word-of-mouth intentions, $W P M$ willingness to pay more

\section{References}

Adweek. (2009). Green is the new black. June 24. http://www.adweek. com/news/advertising-branding/green-new-black-105996. Accessed October 4, 2011.

Aguilera, R. V., Rupp, D. E., Williams, C. A., \& Ganapathi, J. (2007). Putting the s back in corporate social responsibility: A multilevel theory of social change in organizations. Academy of Management Review, 32(3), 836-863.

Aiken, L. S., \& West, S. G. (1991). Multiple regression: Testing and interpreting interactions. Newbury Park, CA: Sage Publications.

Ajzen, I. (1991). The theory of planned behavior. Organizational Behavior and Human Decision Processes, 50(2), 179-211.
Ajzen, I., \& Madden, T. J. (1986). Prediction of goal-directed behavior: Attitudes, intentions, and perceived behavioral control. Journal of Experimental Social Psychology, 22(5), 453-474.

Anderson, J. C., \& Gerbing, D. W. (1988). Structural equation modeling in practice: A review and recommended two-step approach. Psychological Bulletin, 103(3), 411-423.

Armstrong, J. S., \& Overton, T. S. (1977). Estimating nonresponse bias in mail surveys. Journal of Marketing Research, 14(3), 396-402.

Ashforth, B. E., \& Mael, F. (1989). Social identity theory and the organization. Academy of Management Review, 14(1), 20-39.

Bagozzi, R. P., \& Yi, Y. (1988). On the evaluation of structural equation models. Journal of the Academy of Marketing Science, 16(1), 74-94.

Bamberg, S., \& Schmidt, P. (2003). Incentives, morality, or habit? Predicting students' car use for university routes with the models of Ajzen, Schwartz, and Triandis. Environment and Behavior, $35(2), 264-285$

Baron, R. M., \& Kenny, D. A. (1986). The moderator-mediator variable distinction in social psychological research: Conceptual, strategic, and statistical considerations. Journal of Personality and Social Psychology, 51(6), 1173-1182.

Barone, M. J., Miyazaki, A. D., \& Taylor, K. A. (2000). The influence of cause-related marketing on consumer choice: Does one good turn deserve another? Journal of the Academy of Marketing Science, 28(2), 248-262.

Beauchamp, T. (2001). Manipulative advertising. In T. Beauchamp \& N. E. Bowie (Eds.), Ethical theory and business (6th ed., pp. 476-484). Englewood Cliffs: Prentice Hall.

Bergami, M., \& Bagozzi, R. P. (2000). Self-categorization, affective commitment and group self-esteem as distinct aspects of social identity in the organization. British Journal of Social Psychology, 39(4), 555-577.

Bhattacharya, C. B., Korschun, D., \& Sen, S. (2009). Strengthening stakeholder-company relationships through mutually beneficial corporate social responsibility initiatives. Journal of Business Ethics, 85(2), 257-272.

Bhattacharya, C. B., Rao, H., \& Glynn, M. A. (1995). Understanding the bond of identification: An investigation of its correlates among art museum members. Journal of Marketing, 59(4), $46-57$.

Bhattacharya, C. B., \& Sen, S. (2003). Consumer-company identification: A framework for understanding consumers' relationships with companies. Journal of Marketing, 67(2), 76-88.

Bloemer, J., \& Odekerken-Schröder, G. (2007). The psychological antecedents of enduring customer relationships: An empirical study in a bank setting. Journal of Relationship Marketing, 6(1), 21-43.

Bosnjak, M., Tuten, T. L., \& Wittmann, W. W. (2005). Unit (non)response in web-based access panel surveys: An extended planned-behavior approach. Psychology \& Marketing, 22(6), 489-505.

Brehm, J. W., \& Mann, M. (1975). Effect of importance of freedom and attraction to group members on influence produced by group pressure. Journal of Personality and Social Psychology, 31(5), $816-824$.

Brown, T. J., \& Dacin, P. A. (1997). The company and the product: Corporate associations and consumer product responses. Journal of Marketing, 61(1), 68-84.

Browne, M., Sweet, M., Woodburn, A., \& Allen, J. (2005). Urban freight consolidation centres: Final report. Transport Studies Group, University of Westminster, London, November 2.

Cialdini, R. B., \& Goldstein, N. J. (2004). Social influence: Compliance and conformity. Annual Review of Psychology, 55, 591-621. 
Conway, J. M., \& Lance, C. E. (2010). What reviewers should expect from authors regarding common method bias in organizational research. Journal of Business and Psychology, 25(3), 325-334.

Cronin, J. J., Jr., Smith, J. S., Gleim, M. R., Ramirez, E., \& Martinez, J. D. (2011). Green marketing strategies: An examination of stakeholders and the opportunities they present. Journal of the Academy of Marketing Science, 39(1), 158-174.

EcoWatch. (2015). IKEA sees sales of green products soar, sales exceed $\$ 1$ billion in 2014. February 9. http://ecowatch.com/ 2015/02/09/ikea-sales-green-products-soar. Accessed June 13, 2016.

Elkington, J. (1999). Cannibals with forks: The triple bottom line of 21st century business. Oxford: Capstone Publishing.

Fornell, C., \& Larcker, D. F. (1981). Evaluating structural equation models with unobservable variables and measurement error. Journal of Marketing Research, 18(1), 39-50.

Godfrey, P. C., Merrill, C. B., \& Hansen, J. M. (2009). The relationship between corporate social responsibility and shareholder value: An empirical test of the risk management hypothesis. Strategic Management Journal, 30(4), 425-445.

Goldstein, N. J., Cialdini, R. B., \& Griskevicius, V. (2008). A room with a viewpoint: Using social norms to motivate environmental conservation in hotels. Journal of Consumer Research, 35(3), 472-482.

Groza, M. D., Pronschinske, M. R., \& Walker, M. (2011). Perceived organizational motives and consumer responses to proactive and reactive CSR. Journal of Business Ethics, 102(4), 639-652.

Handelman, J. M., \& Arnold, S. J. (1999). The role of marketing actions with a social dimension: Appeals to the institutional environment. Journal of Marketing, 63(3), 33-48.

Hare, R. M. (1984). Commentary. Business \& Professional Ethics Journal, 3(3 \& 4), 23-28.

Harland, P., Staats, H., \& Wilke, H. A. M. (1999). Explaining proenvironmental intention and behavior by personal norms and the theory of planned behaviour. Journal of Applied Social Psychology, 29(12), 2505-2528.

Hayes, A. F. (2012). PROCESS: A versatile computational tool for observed variable mediation, moderation, and conditional process modeling [White paper]. http://afhayes.com/public/pro cess2012.pdf. Accessed February 21, 2017.

Hayes, A. F. (2013-2015). Model templates for PROCESS for SPSS and SAS. http://afhayes.com/public/templates.pdf. Accessed February 21, 2017.

Henderson, T., \& Arora, N. (2010). Promoting brands across categories with a social cause: Implementing effective embedded premium programs. Journal of Marketing, 74(6), 41-60.

Hsu, T. (2011). Skepticism grows over products touted as ecofriendly. Los Angeles Times, May 21. http://articles.latimes. com/2011/may/21/business/la-fi-greenwash-20110521. Accessed October 4, 2011.

Iacobucci, D., Saldanha, N., \& Deng, X. (2007). A meditation on mediation: Evidence that structural equations models perform better than regressions. Journal of Consumer Psychology, 17(2), 139-153.

Kant, I. (1999[1788]). Critique of practical reason. In M. J. Gregor (Ed.), The Cambridge edition of the works of Immanuel Kant: Practical philosophy (pp. 37-108). Cambridge: Cambridge University Press.

Kumar, R., \& Das, T. K. (2007). Interpartner legitimacy in the alliance development process. Journal of Management Studies, 44(8), 1425-1453.

Lance, C. E., Dawson, B., Birkelbach, D., \& Hoffman, B. J. (2010). Method effects, measurement error, and substantive conclusions. Organizational Research Methods, 13(3), 435-455.

Lichtenstein, D. R., Drumwright, M. E., \& Braig, B. M. (2004). The effect of corporate social responsibility on customer donations to corporate-supported nonprofits. Journal of Marketing, 68(4), 16-32.

Lichtenstein, D. R., Netemeyer, R. G., \& Maxham, J. G. (2010). The relationships among manager-, employee-, and customer-company identification: Implications for retail store financial performance. Journal of Retailing, 86(1), 85-93.

Luchs, M. G., Walker Naylor, R., Irwin, J. R., \& Raghunathan, R. (2010). The sustainability liability: Potential negative effects of ethicality on product preference. Journal of Marketing, 74(5), $18-31$.

Luo, X., \& Bhattacharya, C. B. (2006). Corporate social responsibility, customer satisfaction, and market value. Journal of Marketing, 70(4), 1-18.

MacKenzie, S. B., Podsakoff, P. M., \& Podsakoff, N. P. (2011). Construct measurement and validation procedures in MIS and behavioral research: Integrating new and existing techniques. MIS Quarterly, 35(2), 293-334.

Mael, F., \& Ashforth, B. E. (1992). Alumni and their alma mater: A partial test of the reformulated model of organizational identification. Journal of Organizational Behavior, 13(2), 103-123.

Meyer, J. W., \& Rowan, B. (1977). Institutionalized organizations: Formal structure as myth and ceremony. American Journal of Sociology, 83(2), 340-363.

Milieukeur. (2011). Website. http://www.smk.nl/nl/s357/SMK/Pro gramma-s/Milieukeur/c327-Voordelen. Accessed October 4, 2011.

Mohr, L. A., Eroglu, D., \& Scholder Ellen, P. (1998). The development and testing of a measure of skepticsm toward environmental claims in marketers' communications. Journal of Consumer Affairs, 32(1), 30-55.

Mohr, L. A., \& Webb, D. J. (2005). The effects of corporate social responsibility and price on consumer responses. Journal of Consumer Affairs, 39(1), 121-147.

Morgan, R. M., \& Hunt, S. D. (1994). The commitment-trust theory of relationship marketing. Journal of Marketing, 58(3), 20-38.

Muncy, J. A., \& Vitell, S. J. (1992). Consumer ethics: An investigation of the ethical beliefs of the final consumer. Journal of Business Research, 24(4), 297-311.

Nunnally, J. C. (1978). Psychometric theory. New York, NY: McGraw-Hill.

Oom Do Valle, P., Rebelo, E., Reis, E., \& Menezes, J. (2005). Combining behavioral theories to predict recycling involvement. Environment and Behavior, 37(3), 364-396.

Ozcaglar-Toulouse, N., Shiu, E., \& Shaw, D. (2006). In search of fair trade: Ethical consumer decision making in France. International Journal of Consumer Studies, 30(5), 502-514.

Pan, Y., \& Zinkhan, G. M. (2006). Determinants of retail patronage: A meta-analytical perspective. Journal of Retailing, 82(3), 229-243.

Peloza, J., \& Shang, J. (2011). How can corporate social responsibility activities create value for stakeholders? A systematic review. Journal of the Academy of Marketing Science, 39(1), $117-135$.

Perdue, B. C., \& Summers, J. O. (1986). Checking the success of manipulations in marketing experiments. Journal of Marketing Research, 23(4), 317-326.

Podsakoff, P. M., MacKenzie, S. B., Lee, J.-Y., \& Podsakoff, N. P. (2003). Common method bias in behavioral research: A critical review of the literature and recommended remedies. Journal of Applied Psychology, 88(5), 879-903.

Quak, H. J., \& De Koster, M. B. M. (2007). Exploring retailers' sensitivity to local sustainability policies. Journal of Operations Management, 25(6), 1103-1122.

Richardson, H. A., Simmering, M. J., \& Sturman, M. C. (2009). A tale of three perspectives: Examining post hoc statistical techniques for detection and correction of common method variance. Organizational Research Methods, 12(4), 762-800. 
Scholder Ellen, P., Mohr, L. A., \& Webb, D. J. (2000). Charitable programs and the retailer: Do they mix? Journal of Retailing, 76(3), 393-406.

Schuler, D. A., \& Cording, M. (2006). A corporate social performance-corporate financial performance behavioral model for consumers. Academy of Management Review, 31(3), 540-558.

Schwartz, S. H. (1968). Words, deeds, and the perception of consequences and responsibility in action situations. Journal of Personality and Social Psychology, 10(3), 232-242.

Schwartz, S. H. (1977). Normative influences on altruism. Advances in Experimental Social Psychology, 10, 221-279.

Schwartz, S. H., \& Howard, J. A. (1980). Explanations of the moderating effect of responsibility denial on the personal norm-behavior relationship. Social Psychology Quarterly, 43(4), 441-446.

Sen, S., \& Bhattacharya, C. B. (2001). Does doing good always lead to doing better? Consumer reactions to corporate social responsibility. Journal of Marketing Research, 38(2), 225-243.

Sen, S., Bhattacharya, C. B., \& Korschun, D. (2006). The role of corporate social responsibility in strengthening multiple stakeholder relationships: A field experiment. Journal of the Academy of Marketing Science, 34(2), 158-166.

Shaw, D., \& Shiu, E. (2002). The role of ethical obligation and selfidentity in ethical consumer choice. International Journal of Consumer Studies, 26(2), 109-116.

Shaw, D., \& Shiu, E. (2003). Ethics in consumer choice: A multivariate modelling approach. European Journal of Marketing, 37(10), 1485-1498.

Shaw, D., Shiu, E., \& Clarke, I. (2000). The contribution of ethical obligation and self-identity to the theory of planned behaviour: An exploration of ethical consumers. Journal of Marketing Management, 16(8), 879-894.

Sher, S. (2011). A framework for assessing immorally manipulative marketing tactics. Journal of Business Ethics, 102(1), 97-118.

Smith, J. R., Terry, D. J., Manstead, A. S. R., Louis, W. R., Kotterman, D., \& Wolfs, J. (2008). The attitude-behavior relationship in consumer conduct: The role of norms, past behavior, and selfidentity. Journal of Social Psychology, 148(3), 311-333.

Suchman, M. C. (1995). Managing legitimacy: Strategic and institutional approaches. Academy of Management Review, 20(3), 571-610.

Van Rooijen, T., \& Quak, H. (2010). Local impacts of a new urban consolidation centre-The case of Binnenstadervice.nl. Procedia Social and Behavioral Sciences, 2(3), 5967-5979.
Villarán, A. (2015). Irrational advertising and moral autonomy. Journal of Business Ethics. doi:10.1007/s10551-015-2813-z.

Vitell, S. J. (2015). A case for consumer social responsibility (CnSR): Including a selected review of consumer ethics/social responsibility research. Journal of Business Ethics, 130(4), 767-774.

Vitell, S. J., \& Muncy, J. (2005). The Muncy-Vitell consumer ethics scale: A modification and application. Journal of Business Ethics, 62(3), 267-275.

Vlachos, P. A. (2012). Corporate social performance and consumerretailer emotional attachment: The moderating role of individual traits. European Journal of Marketing, 46(11/12), 1559-1580.

Vlachos, P. A., Tsamakos, A., Vrechopoulos, A. P., \& Avramidis, P. K. (2009). Corporate social responsibility: Attributions, loyalty, and the mediating role of trust. Journal of the Academy of Marketing Science, 37(2), 170-180.

Wagner, T., Lutz, R. J., \& Weitz, B. A. (2009). Corporate hypocrisy: Overcoming the threat of inconsistent corporate social responsibility perceptions. Journal of Marketing, 73(6), 77-91.

Wall, R., Devine-Wright, P., \& Mill, G. A. (2007). Comparing and combining theories to explain pro-environmental intentions: The case of commuting-mode choice. Environment and Behavior, 39(6), 731-753.

Woller, K. M. P., Buboltz, W. C., \& Loveland, J. M. (2007). Psychological reactance: Examination across age, ethnicity, and gender. American Journal of Psychology, 120(1), 15-24.

World Commission on Environment and Development. (1987). Our common future. New York, NY: Oxford University Press.

Yoon, Y., Gürhan-Canli, Z., \& Schwarz, N. (2006). The effect of corporate social responsibility (CSR) activities on companies with bad reputations. Journal of Consumer Psychology, 16(4), 377-390.

Zhang, J., \& Bloemer, J. M. M. (2008). The impact of value congruence on consumer-service brand relationships. Journal of Service Research, 11(2), 161-178.

Zhao, X., Lynch, J. G., Jr., \& Chen, Q. (2010). Reconsidering Baron and Kenny: Myths and truths about mediation analysis. Journal of Consumer Research, 37(2), 197-206.

Zimmerman, M. A., \& Zeitz, G. J. (2002). Beyond survival: Achieving new venture growth by building legitimacy. Academy of Management Review, 27(3), 414-431. 